\title{
Condiçóes de trabalho em uma cozinha industrial e distúrbios osteomusculares de trabalhadores
}

\author{
Maria do Carmo Baracho de Alencara , Thayná Almeida Cavalcanti ${ }^{\mathrm{b}}$, \\ Janaína Bussola Montrezor ${ }^{\mathrm{b}}$ \\ aProfessora Doutora, Departamento de Gestão e Cuidados em Saúde, Universidade Federal de São Paulo - \\ UNIFESP, Campus da Baixada Santista, Santos, SP, Brasil

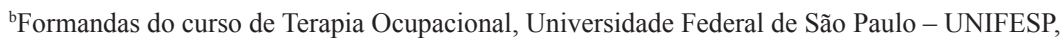 \\ Campus da Baixada Santista, Santos, SP, Brasil
}

\begin{abstract}
Resumo: Neste artigo apresenta-se um estudo, que não é pesquisa e sim relato de experiência de estágio do curso de Terapia Ocupacional na área de Saúde e Trabalho. O objetivo foi analisar as condições de trabalho em uma cozinha industrial de escola de ensino fundamental, da Baixada Santista-SP, e as relações com distúrbios osteomusculares de cozinheiras. Os materiais e métodos utilizados consistiram de elaboração e aplicação de questionário contendo dados demográficos, relacionados ao trabalho, e questões do questionário nórdico de sintomas osteomusculares, também levantamentos de alguns dados antropométricos, de tarefas, e ocorreram observações sistemáticas de algumas atividades de trabalho com base na ergonomia, entre outros. Participaram do estudo cinco trabalhadores do gênero feminino e com idade entre 41 e 53 anos. As regiões acometidas pelos distúrbios osteomusculares foram punhos/mãos, ombros e quadril/coxas, entre outras. Foram encontrados alguns aspectos organizacionais e psicossociais do trabalho que ressaltaram a importância dessas análises. Como experiência, apresentam-se, entre outros, as discussões e contribuições da Terapia Ocupacional junto ao estudo dos distúrbios osteomusculares relacionados ao trabalho (DORT).
\end{abstract}

Palavras-chave: Condições de Trabalho, Cozinheira, Transtornos Traumáticos Repetitivos, Terapia Ocupacional.

\section{Working conditions in industrial kitchens and musculoskeletal disorders of workers}

\begin{abstract}
This article presents a study based on an experience report of Occupational Therapy internship in Occupational Health. The objective of this study was to analyze the working conditions in an industrial kitchen of an Elementary School near Santos city, state of Sao Paulo and the appearance of musculoskeletal disorders. The materials and methods consisted in the elaboration and application of a questionnaire with demographic data related to work and the questions of the Nordic musculoskeletal disorder questionnaire. In addition, anthropometric and tasks surveys and systematic observations of some activities based on Ergonomics were performed. Five female workers aged in between 41 and 53 participated in this study. The musculoskeletal regions referred were wrists/hands, shoulders, hips/thighs, among others. Some organizational and psychosocial aspects that highlight the importance of these evaluations were verified. As an experience, it presents discussions and contributions of the Occupational Therapy to work-related musculoskeletal disorders (WMSDs).
\end{abstract}

Keywords: Working Conditions, Cook, Repetitive Strain Injury, Occupational Therapy.

Autor para correspondência: Maria do Carmo Baracho de Alencar, Universidade Federal de São Paulo, Rua Silva Jardim, 136, Vila Mathias, Campus Baixada Santista, CEP 11015-020, Santos, SP, Brasil, e-mail: belinha.alencar1@gmail.com; alencar@unifesp.br

Recebido em 9/11/2010; $1^{\text {a }}$ Revisão em 16/5/2011; Aceito em 11/8/2011. 


\section{Introdução}

O mundo do trabalho tem sofrido intensas mudanças nos últimos anos, com alteraçôes nos modos de organização do trabalho, nas exigências de produção, introdução de novas tecnologias, aceleração do ritmo de trabalho, exigências por metas de produçáo, entre outros, e às vezes em situaçóes de empregabilidade instáveis, que vêm contribuindo para o adoecimento de trabalhadores tanto no aspecto físico quanto mental em vários setores de trabalho (LANCMAN, 2004). Inúmeras pesquisas e intervençôes têm sido realizadas visando à melhoria das condiçóes de trabalho, uma vez que estas podem afetar a saúde do trabalhador. É incontestável que o sujeito passa grande parte do tempo de vida no ambiente de trabalho, e é portanto necessária a constante preocupação quanto a segurança, bem-estar e conforto dos trabalhadores, e de intervençóes que visem melhorias nas condições de trabalho.

Uma das formas de adoecimento relacionado ao trabalho contemporâneo são as lesões por esforços repetitivos (LER) ou distúrbios osteomusculares relacionados ao trabalho (DORT), que continuam crescendo entre a população de trabalhadores. No Brasil, começou a adquirir expressão em número e relevância social segundo o Ministério da Saúde (BRASIL, 2001) a partir da década de 80 , tornando-se um grave problema de saúde pública e social em função da magnitude e abrangência.

Segundo o Ministério da Saúde (BRASIL, 2001), os distúrbios osteomusculares relacionados ao trabalho (DORT) são danos decorrentes da utilização excessiva, imposta ao sistema músculo-esquelético, e da falta de tempo para a recuperação, entre outros. A etiologia é multifatorial, e caracterizam-se pela ocorrência de vários sintomas concomitantes ou não, de aparecimento insidioso, tais como dor, parestesia, sensação de peso e fadiga. Os DORTs afetam os músculos, tendôes, ligamentos, articulaçốes, nervos periféricos, etc.; incluindo: inflamaçôes em tendóes (tendinites), tenossinuvites, bursites, compressões nervosas, entre outros (PUNNETT; WEGMAN, 2004). Afetam segundo os mesmos autores várias regiōes corporais, como lombar, ombros, antebraço, punhos/mãos, entre outros; havendo uma atenção recentemente dada também para regiōes de membros inferiores. As regióes corporais afetadas são em geral aquelas mais utilizadas (requisitadas em açóes) durante as atividades de trabalho.

Segundo o Ministério da Saúde (BRASIL, 2006), a alta prevalência das LER/DORT tem sido explicada pelas transformaçóes no mundo do trabalho, onde a organização tem se caracterizado pelo estabelecimento de metas e produtividade, entre outros, e sem levar em conta os trabalhadores e seus limites físicos. No caso de um ambiente de trabalho, quando se fala em prevenção de distúrbios osteomusculares são os aspectos biomecânicos, com análises de posturas e movimentos, equipamentos e mobiliários, os mais tradicionalmente analisados, e são em geral desconsiderados os aspectos ligados à organização do trabalho, também muito importantes (CHIAVEGATO FILHO; PEREIRA JUNIOR, 2004).

A Organização do Trabalho prescreve as normas e parâmetros das empresas, de quem deve executar as tarefas, de que forma e quando, qual a qualidade exigida, equipamentos necessários e disponíveis, e quantidades a serem produzidas, entre outros. Merlo et al. (2003) citam elementos da organizaçáo do trabalho e relacionados às LER/DORTs, como a pressão no trabalho, restrição da comunicação entre os trabalhadores, pouco reconhecimento no trabalho e o náo emprego de novas tecnologias para aliviar a carga de trabalho, entre outros. Para Lancman (2004), em relação à saúde no trabalho, vários fatores podem agravar-se conforme as exigências impostas pela organização do trabalho.

Entre os modelos teóricos que estudam o trabalho, está a ergonomia. Na ergonomia historicamente existem duas correntes, a primeira, mais antiga, de origem na Inglaterra, está mais centrada nas características psicofisiológicas do homem e orientada para a concepção de dispositivos técnicos; e a segunda, de origem francofônica, sem desconsiderar as características psicofisiológicas do homem, é mais analítica e prioriza um estudo da análise da atividade do trabalho, entendendo o trabalhador como ator no processo de trabalho (ABRAHÁO; PINHO, 1999). Apesar de diferentes abordagens entre as duas correntes da ergonomia, uma pode vir a complementar a outra, em alguns aspectos.

Pela abordagem teórica da ergonomia francofônica, em todo trabalho existem tarefas e atividades. Para Falzon (2007), a tarefa é o que se deve fazer, o que é prescrito pela organização, e a atividade é o que é feito, o que o sujeito mobiliza para realizar a tarefa. Segundo o mesmo autor, a atividade de trabalho não se reduz ao aspecto físico (biomecânico) nem ao comportamento, que seria a parte observável; inclui o observável e o não observável. A atividade (o trabalho real) é fruto da execução da tarefa, e é o que o trabalhador faz para atingir os objetivos impostos da tarefa, e o trabalhador que executa tem uma história de vida, experiências, valores, crenças, desejos, entre outros. Para Guérin et al. (1997), há uma distância entre o que é prescrito e o real, e é 
nessa distância que ocorrem os conflitos internos e externos ao trabalhador.

Ainda, todo trabalho possui cargas de trabalho que envolvem diversas atividades dos trabalhadores (mentais, motoras, fisiológicas etc.) que são necessárias para a realização das tarefas. Carga de trabalho para Falzon e Sauvagnac (2007) é o grau de mobilização físico, cognitivo e psíquico do trabalhador. Segundo os mesmos autores é ambíguo, pode se referir ao nível de exigência de uma tarefa ou às consequências da tarefa. A carga de trabalho está diretamente relacionada às exigências do trabalho e as formas de enfrentamento do trabalhador (WISNER, 1994).

Em relação aos diversos setores de trabalho, a cozinha industrial é um dos serviços de alimentação que vem sofrendo grandes mudanças e tenta se adequar para elevar a produtividade. A preparaçáo dos alimentos em uma cozinha industrial é um dos serviços de alimentação que sofrem mudanças devido à introdução de tecnologias que visam maximizar a produção (SIQUEIRA et al., 2000). As atividades desenvolvidas em cozinhas industriais caracterizam-se por manipulação manual intensa durante o processo de preparo dos alimentos e limpeza do local de trabalho. A realização dessas tarefas vem acompanhada de movimentos repetitivos de membros superiores e coluna, levantamento de pesos excessivos e permanência na postura em pé por períodos prolongados de tempo (CASAROTTO; MENDES, 2000). Segundo Assunção (2008), os trabalhadores muitas vezes são levados a um quadro de insatisfaçóes e fadiga, diante de condiçóes precárias de trabalho, com queda de produtividade, além de problemas de saúde e acidentes no trabalho.

Em estudo de Ghisleni e Merlo (2005) com trabalhadores contemporâneos acometidos por LER/ DORT, de 29 profissôes encontradas o de cozinheiro estava entre as de maior prevalência, depois do ramo calçadista e de limpeza. Casarotto e Mendes (2000) identificaram que os fatores de risco responsáveis pelo aparecimento dos distúrbios osteomusculares, incluindo lesôes no ombro, estão presentes em todas as atividades desenvolvidas nas cozinhas, com movimentos inadequados para membros superiores e força manual excessiva. Segundo Haukka et al. (2006), a maior prevalência em três meses de dores osteomusculares em 495 cozinheiras do gênero feminino foi em regiáo cervical, lombar e punhos/ mãos, sendo que $73 \%$ tiveram dores em pelo menos duas regiōes.

A proposta deste artigo, que não é resultado de pesquisa e sim relato de experiência de estágio profissionalizante em Terapia Ocupacional na área de Saúde e Trabalho, justifica-se no pressuposto de que o estudo da relação entre saúde e trabalho é um importante espaço de atuação do Terapeuta Ocupacional, e que são necessárias produções teóricas que apresentem e fundamentem propostas de intervençấo. Nesse sentido, o objetivo foi o de analisar as condições de trabalho em uma cozinha industrial de escola de ensino fundamental na cidade de Santos, SP, e aspectos relacionados aos distúrbios osteomusculares de cozinheiras.

\section{Material e métodos}

O presente estudo foi realizado durante o período de estágio de quarto ano do curso de Terapia Ocupacional da Universidade Federal de São Paulo (Unifesp), campus da Baixada Santista em 2009, onde as estagiárias atendiam durante três dias/ turnos por semana pacientes afastados do trabalho por LER/DORT, e um dia além desses três dias era destinado à atividade externa e com enfoque em estudos e análises ergonômicas preferencialmente em ambientes de trabalho relacionados aos casos atendidos.

Inicialmente, foi selecionado para o estudo o local de trabalho de uma trabalhadora afastada (escolhida aleatoriamente entre os pacientes atendidos pelos alunos), cuja profissão era cozinheira e apresentava o diagnóstico clínico de tendinopatia do supra espinhal em ombro, dado obtido através de avaliação inicial em estágio. Foi realizado um contato telefônico com a escola (local de trabalho da paciente) pela professora responsável pelo estágio, para autorização prévia da proposta de estudo e intervenção, e após autorizaçáo foram realizadas visitas iniciais ao local.

Após as primeiras visitas, foi elaborado junto às estagiárias um questionário contendo dados demográficos (idade, gênero, escolaridade), dados relacionados ao trabalho, como profissáo atual, tempo de atuação na profissão, carga horária de trabalho, profissão anterior, entre outros. Também levantamento de dados referente às queixas de sintomas osteomusculares, baseado no Questionário Nórdico de Sintomas Osteomusculares - QNSO (PINHEIRO; TRÓCCOLI; CARVALHO, 2002), com questôes complementares como sintomas nos últimos 30 dias, para aplicação sob forma de entrevista inicial junto aos trabalhadores. Também foram obtidos alguns dados antropométricos como: estatura dos trabalhadores (através de fita métrica com precisão de milímetros, fixada na parede, e avaliado em posição ortostática, braços estendidos ao longo do corpo, pés unidos, com superfícies posteriores do calcanhar estando descalço, e com cintura pélvica, escapular e regiáo occipital em contato com a parede), 
comprimento das panelas e altura do fogão; também através do mesmo instrumento sem a fixação na parede. Além de registros de pesos de caixas obtidos nas embalagens, como complementos ao estudo.

Posteriormente ocorreram levantamentos das tarefas e observaçóes sistemáticas de algumas atividades de trabalho, com base na ergonomia. Para as observaçóes e registros das atividades utilizou-se uma câmera fotográfica marca Sony Cyber-Shot 5.1 mega pixels (modelo DSC-P100) e registros de falas e relatos durante o trabalho, com caneta e papel. Todos os trabalhadores aceitaram participar voluntariamente de todas as etapas do estudo, e houve autorização tanto das trabalhadoras quanto da instituição para os registros.

\section{Resultados e discussões}

A cozinha ficava dentro de uma escola de ensino fundamental na Baixada Santista, SP, e tinha cerca de 400 alunos de ambos os gêneros. Participaram do estudo cinco de um total de seis - uma era a trabalhadora que estava afastada do trabalho. Todas do gênero feminino, com faixa etária entre $41 \mathrm{e}$ 53 anos de idade, tempo de atuaçáo na profissão de dois meses a nove anos, escolaridade de Ensino Médio, e todas com horário de trabalho de 8 horas/diárias, turno diurno. Duas com registro de trabalho como cozinheira e as demais auxiliares de cozinha. Quanto à estatura das trabalhadoras, a média foi de 1,64 $\mathrm{m}$ $(\mathrm{DP}=0,043)$.

O expediente de trabalho era das $6 \mathrm{~h} 30$ às $14 \mathrm{~h} 30$ (para três trabalhadoras, sendo que uma estava afastada), das $9 \mathrm{~h}$ às $17 \mathrm{~h}$ (para duas trabalhadoras) e das $11 \mathrm{~h}$ às $17 \mathrm{~h}$ (para uma trabalhadora). Em relação ao espaço físico havia dois locais (cozinha e despensa), com poucas janelas dispostas no alto, tendo quatro portas de saída, pias e armários embaixo, um ventilador no teto, um fogão no centro da cozinha, dois freezers e uma geladeira dispostos em diferentes posiçóes e duas bancadas. Entre os equipamentos utilizados: um liquidificador industrial e um multiprocessador de legumes.

Os alunos da escola faziam três refeiçóes: desjejum, almoço, e lanche da tarde. As trabalhadoras começavam a preparar o lanche da manhá às $6 \mathrm{~h} 30$, que era servido das $8 \mathrm{~h} 30$ às $9 \mathrm{~h} 30$, e paralelamente iniciavam o preparo do almoço às $8 \mathrm{~h}$, que deveria estar pronto às $11 \mathrm{~h}$, e nesse horário deveriam almoçar, antes de servir o almoço das $11 \mathrm{~h} 30$ às $13 \mathrm{~h}$. Um lanche à tarde era servido das $14 \mathrm{~h} 20$ às $15 \mathrm{~h} 30$. O consumo diário de alimentos era grande, por exemplo, todos os dias utilizavam uma caixa de leite com 12 unidades, e por dia faziam cerca de 500 refeiçóes. Os alunos podiam repetir os pratos e sobremesas, e o cardápio variava conforme orientaçóes da nutricionista.

\section{Os sintomas dos trabalhadores}

Em relação aos sintomas das trabalhadoras, eles estiveram presentes tanto nos últimos 30 dias quanto nos últimos 7 dias em todas, sendo as queixas por regiōes acometidas: quatro em punhos/mãos, três em ombros, três em quadril/coxas, três em joelhos, uma em lombar, e uma em cervical; havendo mais de uma queixa em algumas trabalhadoras. Entre os sintomas mais referidos estava a dor e havia sintomas também referidos nos últimos doze meses. Em estudo de Casarotto e Mendes (2000) as regióes lombar, ombros, punhos/mãos foram as regiōes mais acometidas por queixas de desconforto. E nos últimos 12 meses uma trabalhadora havia se afastado do trabalho por lesão osteomuscular (paciente que era atendida em estágio).

\section{As tarefas e atividades de trabalho}

As principais tarefas em geral consistiam de: organizar, preparar os alimentos (verificando o cardápio), cozinhar e servir as refeiçôes dos alunos, lavar e guardar os equipamentos e instrumentos de trabalho, contar, registrar e organizar na despensa os alimentos, limpar e lavar a cozinha (exceto as janelas externas e coifa), equipamentos e utensílios, entre outros, sendo a tarefa de cozinhar os alimentos de responsabilidade das cozinheiras. Através de informaçôes de colegas, foi verificado que a cozinheira afastada do trabalho com lesão em ombro ficava frequentemente responsável pelas tarefas relacionadas ao cozinhar no fogáo. Durante a realização das tarefas, as trabalhadoras utilizavam tocas, aventais, luvas e sapatos antiderrapantes.

A distribuição das tarefas diárias era determinada pelas duas trabalhadoras que chegavam primeiro no período da manhã e passavam as divisóes para as que chegavam às $9 \mathrm{~h}$, determinando quem iria cortar os legumes e verduras, quem iria lavar a louça e servir os alunos, quem pegaria os alimentos na despensa etc.

Para as observaçóes sistemáticas foram selecionadas as tarefas: armazenar e guardar alimentos na despensa, preparar os alimentos (cozimento) no fogão e a lavagem de louças, copos, utensílios, panelas e caldeirōes. Essas tarefas foram selecionadas a partir 
de percepçóes de esforços físicos por algumas trabalhadoras, havendo outras tarefas percebidas como de esforço, como lavar e cortar os legumes e frutas. Essas últimas não foram selecionadas para as observaçôes, pela pouca disponibilidade de horários das alunas do estágio.

Os alimentos chegavam duas vezes por semana em caixas (arroz, feijão, açúcar, leite etc.), e os legumes, verduras e frutas chegavam diariamente. Tudo era armazenado em balcão ou no chão da cozinha, e assim que chegavam as caixas com os alimentos estes já deveriam ser armazenados na despensa, para evitar de impedir passagens e/ou diminuir o espaço de circulação na cozinha. Também era necessário ter conhecimento sobre o cardápio do dia, para já deixarem separados os alimentos, entre outras tarefas.

A despensa consistia de um espaço físico reduzido ao lado da cozinha, contendo um freezer e quatro prateleiras em paredes, onde eram armazenados os alimentos em caixas. Havia prateleiras altas e baixas, e nas prateleiras mais baixas encontravam-se os alimentos que eram utilizados diariamente e mais pesados, como pacotes de arroz, caixas de leite e latarias. Para armazenar e pegar os alimentos na despensa (diariamente), as trabalhadoras tiravam de prateleiras caixas de 10 a $15 \mathrm{~kg}$ de alimentos, em prateleiras altas, onde tinham que subir em escadas, com risco de quedas, para alcançá-las. A Figura 1 demonstra a retirada de caixas de alimentos de uma das prateleiras da despensa.

Foram observadas exigências físicas, especialmente em alguns movimentos articulares em determinadas amplitudes que são consideradas de risco para lesóes osteomusculares, e transporte de carga (caixas). Dul e Weerdmeester (2004) referem que manipulaçóes fora do alcance dos braços, exigem movimentos do tronco; e recomendam que se açôes de máos e cotovelos forem inevitáveis em alturas acima do nível do ombro, que sejam em duração limitada.

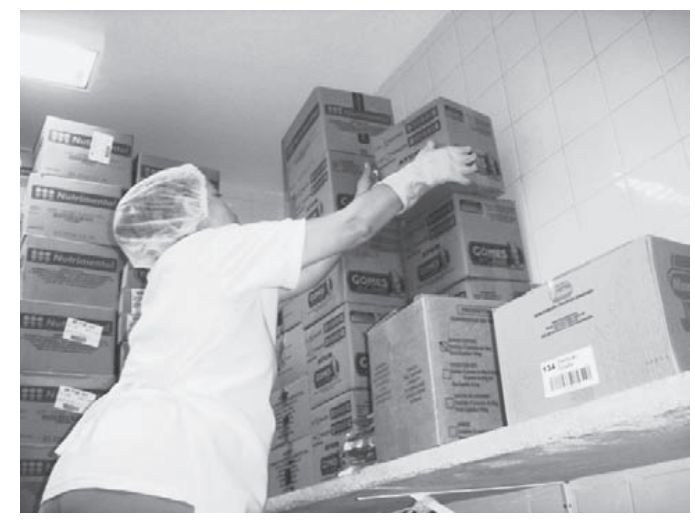

Figura 1. Retirada de caixas com alimentos da despensa.
Manipulaçóes de cargas devem ser evitadas sem auxílio, e/ou treinadas, e o terapeuta ocupacional pode também fornecer orientaçóes gerais preventivas. Para Oliveira (2005) é com alteraçóes de posturas, entre outros, que o trabalhador consegue vencer os constrangimentos que lhe são impostos.

Quanto às exigências em geral no trabalho, elas são físicas e mentais. As exigências físicas englobam as sensório-motoras que são as açôes realizadas durante todos os processos da atividade. As exigências mentais podem ser cognitivas e psíquicas (afetivas). No caso das cozinheiras as exigências cognitivas são: ter conhecimento sobre o preparo dos alimentos, conhecimento sobre a proporção de quantidades dos alimentos e temperos, a noção do tempo necessário para as tarefas, entre outros. Há exigências físicas no trabalho das cozinheiras e auxiliares, que são: rapidez, frequência e repetitividade das açóes, entre outros. Deve-se ter em mente as inter-relaçóes entre as exigências físicas e mentais, uma vez que as açóes (nas atividades) envolvem os órgãos dos sentidos, percepção do trabalhador, entre outros, e são complexas. Por exemplo, quando é exigida rapidez nas açóes esse fato pode fazer com que sejam elevadas as exigências cognitivas. As exigências psíquicas (cargas afetivas) náo são analisadas pelo modelo teórico da ergonomia (exemplo: ter que estar sempre de bom humor ao lidar com o supervisor).

Em observaçôes, tanto os armazenamentos quanto as retiradas das caixas foram executados em ritmo acelerado, para que náo se perdesse muito tempo e prejudicasse o tempo necessário às demais tarefas. Outras situaçôes críticas foram observadas, como armazenamento e/ou retirada de caixas pesadas sem auxílio de colega, retirada de mais de uma caixa por vez pela pressa, risco de quedas, pouco espaço físico, entre outras.

Preparar os alimentos (cozimento) junto ao fogão envolvia desde a preparação e separação dos utensílios necessários, colocação dos alimentos na panela ou caldeirão, água, o mexer e remexer os alimentos, colocar temperos, entre outros; acompanhando o cozimento até o preparo final. Havendo variaçóes também quanto ao modo de preparo, como, por exemplo, de cozido para assado, de assado para frito, com o uso do forno ou não etc. Há uma grande variedade no trabalho da cozinha, e a realizaçáo de açóes não obedece a uma ordem simples nem linear; começam a cortar uma abóbora, param e vão lavar o arroz, depois vão cortar os legumes, havendo necessidade de cooperação (SILVA; BRITO; ATAHYDE, 2004). Quanto ao posto de trabalho específico, a altura do fogão foi de $85 \mathrm{~cm}$, havendo um pé de $8 \mathrm{~cm}$ adicionado, totalizando a altura do fogáo total de $93 \mathrm{~cm}$. As panelas ficavam armazenadas 
em armários embaixo de balcôes e pias e tinham diferentes comprimentos: caldeirão pequeno com $26,5 \mathrm{~cm}$, panela menor com $18 \mathrm{~cm}$, caldeirão grande com $36,5 \mathrm{~cm}$, panela maior com $23 \mathrm{~cm}$. Analisando, a altura total (fogão + pé + caldeirão maior) era aproximadamente de $1,29 \mathrm{~m}$, dado que pelas estaturas médias das trabalhadoras $(1,64 \mathrm{~m})$ pode favorecer a necessidade de elevação dos braços para facilitar o mexer/remexer os alimentos nas panelas ou caldeiróes até o fundo, sendo um risco para lesóes em ombros pela repetitividade observada, conforme demostrado na Figura 2:

$\mathrm{O}$ uso de panelas grandes era necessário para elas darem conta do trabalho, porque havia um único fogão, como expresso na fala: "tem que fazer nas panelas grandes, porque a gente faz tudo de uma vez, as bocas do fogão são poucas, se for panela pequena...." Mesmo sendo as questôes antropométricas foco de estudo da ergonomia de corrente inglesa/americana, esse dado para o risco de distúrbio osteomuscular em região de ombros pode ser relevante (altura do fogão total: fogão + pé), necessitando de maiores investigaçóes, especialmente por ser o principal posto de trabalho da trabalhadora afastada. Salienta-se, aqui, a importância da participação dos trabalhadores em decisôes e antes de qualquer mudança efetiva em postos de trabalho, caso necessário. Vários aspectos estão envolvidos no processo de adoecimento, sendo este apenas um dos possíveis riscos.

Ainda, precisavam muitas vezes de auxílio de colegas para o transporte de panelas cheias que eram pesadas até as pias, ou de uma pia para outra, quando uma pia estava entupida (fato que ocorria com certa frequência), e nem sempre havia uma trabalhadora disponível no momento para essa ajuda. Havia também pouco espaço livre em balcóes para a colocação do alimento até a preparação dos pratos. Movimentos repetitivos de flexão e abdução do ombro associados ao carregamento de peso, empurrar e puxar objetos, entre outros, são fatores de risco para lesôes de ombro (MENDONÇA JUNIOR; ASSUNÇÃO, 2005).

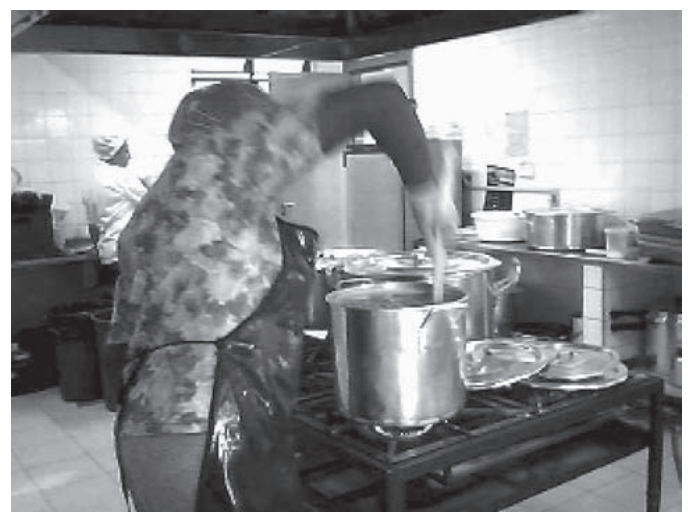

Figura 2. O mexer/remexer os alimentos na panela.
Em relação às lavagens de panelas e caldeiróes, estas eram realizadas em tanque pelo fato de serem grandes, e os pratos, copos, utensílios, talheres, entre outros, eram em geral lavados em pias. Outras trabalhadoras colocavam as panelas e caldeiróes no tanque; e pratos, copos, utensílios etc. ficavam empilheirados nas pias. As lavagens começavam logo após as primeiras refeiçóes serem servidas, e continuavam até a finalização. Essas tarefas exigiam manutenção de postura em pé com inclinação do tronco à frente, que conforme o tempo de permanência e amplitude dos ombros pode sobrecarregar a região lombar. Houve também um ritmo acelerado e repetitividade de trabalho observados, para darem conta da lavagem das panelas e caldeirôes, que faziam em geral depois da lavagem de pratos, copos e utensílios, além de terem de guardá-los. O espaço livre para o armazenamento era pequeno, e uma colega às vezes auxiliava no enxugamento destes quando estavam se acumulando. As trabalhadoras também deveriam utilizar luvas pelo intenso contato com detergente, entre outros, mas nem sempre utilizavam. Na Figura 3, a lavagem de panelas e caldeiróes no tanque.

Os alunos, conforme relatos, eram liberados através de sinal para o almoço, e isso ocorria para várias turmas ao mesmo tempo. Algumas situaçóes

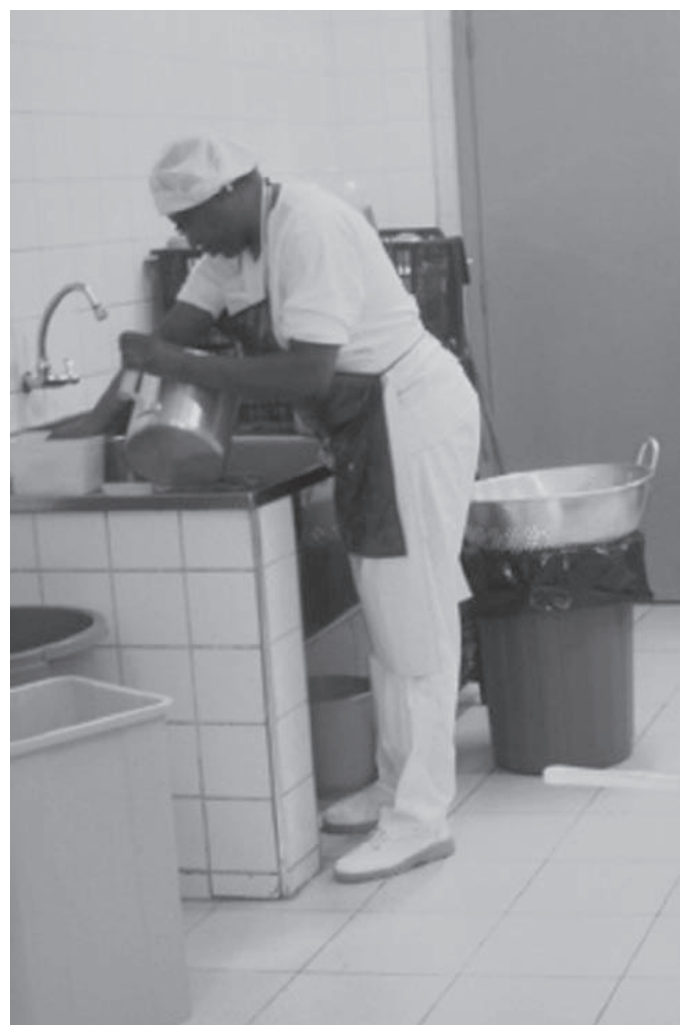

Figura 3. Lavagem de panelas ou caldeirões no tanque. 
de falta de professores faziam com que turmas fossem liberadas antes do horário previsto, havendo pressôes diversas para que o horário do almoço fosse adiantado, o que apressava ainda mais o serviço. Outra situação que gerava sobrecargas físicas e mentais relatada foi que no horário considerado de "pico" para o almoço algumas vezes uma das funcionárias era deslocada para levar refeiçôes para outros funcionários do setor administrativo, pois já estavam com uma trabalhadora a menos (uma já estava afastada do trabalho).

Ritmos acelerados de trabalho, pressão temporal, entre outros, podem fazer com que o trabalhador vá além de suas capacidades físicas no intuito de "dar conta do trabalho", e são riscos para o surgimento de distúrbios osteomusculares. Não somente a saúde física, mas também a saúde mental pode ser afetada. Colares e Freitas (2007) citam em estudos situaçóes específicas de trabalho que afetam a saúde mental, por causarem aborrecimentos e estresse.

O intervalo para almoço das trabalhadoras ocorria em geral durante 15 minutos, e elas se alimentavam sem utilizaçáo de mesa, muitas vezes em pé. Em relação ao intervalo para o almoço, uma auxiliar de cozinha fala: "não dá tempo de almoçar com calma". Horas extras também eram realizadas com frequência, sendo sugerido um rodízio mais organizado nas distribuiçóes das tarefas, além da questão de contratar alguém para substituir provisoriamente a trabalhadora afastada. Náo se pretendeu neste estudo analisar as demais tarefas das trabalhadoras, porém estas podem gerar sobrecargas físicas e mentais ao longo do turno de trabalho.

A presença de sintomas osteomusculares entre as trabalhadoras, tanto nos últimos 12 meses, últimos 30 e 7 dias, gera preocupação quanto ao possível agravamento dos quadros. Em estudo de Paiva e Cruz (2009), as trabalhadoras declararam sentir dores osteomusculares no período de trabalho. Isso leva ao questionamento sobre o que faz o trabalhador "suportar" esses sintomas durante o trabalho.

Quanto ao aspecto ambiental relacionado à temperatura, na cozinha em alguns dias, quando estava calor (temperatura externa em torno de $33^{\circ}-35^{\circ}$ ), a temperatura interna aparentemente náo era aliviada pelo ventilador e janelas abertas, como na fala de uma auxiliar de cozinha: "é muito quente aqui!". Não havia controle sobre a temperatura ambiente, nem sobre possíveis ruídos, qualidade do ar etc.

Houve situaçôes em que ocorriam "tensão", e isso pode induzir a métodos impróprios de execuçáo, como, por exemplo, executar um movimento com maior força muscular, em decorrência de frustaçóes no trabalho (SMITH; CARAYON, 1996). Situações de tensão podem levar ao desgaste junto ao trabalhador.
Mesmo não sendo papel da ergonomia, visto os limites de seu objeto e conceitos, analisar processos subjetivos em situaçóes de trabalho, ela pode dar fundamental contribuição para explicar quando e por que os trabalhadores se estressam (ASSUNÇÃO; LIMA, 2010).

Durante o estudo, as estagiárias buscaram conscientizar essas trabalhadoras quanto aos cuidados durante as análises, e alguns dados eram discutidos entre elas. A Terapia Ocupacional em Saúde e Trabalho pode contribuir satisfatoriamente com análises das condiçóes de trabalho e com outras intervençóes para a prevenção de distúrbios osteomusculares. Como propostas de intervençóes junto às trabalhadoras, técnicas da terapia corporal utilizadas pela Terapia Ocupacional, que visem melhorar a consciência corporal, e para um reconhecimento dos próprios limites físicos e atividades que visem um relaxamento corporal são indicadas. São fundamentais também as intervençóes em grupo terapêutico da Terapia Ocupacional e/ou interdisciplinares com a presença do Terapeuta Ocupacional , para promover reflexóes e discussões em grupo sobre os conflitos e dificuldades existentes, entre outros. O Terapeuta Ocupacional deve ressaltar também a importância de boas relaçôes interpessoais e de cooperação no trabalho (contexto social do trabalho).

\section{Considerações finais}

Várias questôes de risco foram encontradas para o surgimento de distúrbios osteomusculares, como posturas e movimentos de risco, manuseio de panelas pesadas, ritmo acelerado, repetitividade de movimentos, problemas nas divisóes das tarefas, poucas pausas, postos de trabalho e espaço físico inadequados, número insuficiente de trabalhadores, ausência de conforto térmico, entre outros. Alguns aspectos sofrem influências direta ou indiretamente da organização do trabalho, portanto esses aspectos são importantes e necessitam ser aprofundados.

Não foi objetivo realizar um estudo aprofundado, uma vez que se trata de relato de experiência prática de alunos em estágio profissionalizante de quarto ano do curso de Terapia Ocupacional, havendo limitaçóes no estudo. Como experiência de aprendizado as alunas puderam vivenciar a prática simplificada de uma análise do trabalho em situação real, e em local de onde trabalhava uma paciente atendida em estágio e já afastada por LER/DORT.

Recomenda-se uma pesquisa para aprofundar as questóes desse relato de experiência e sobre as outras questóes trazidas neste estudo e em relaçáo às condiçóes de trabalho em cozinhas de escolas de ensino fundamental. 


\section{Referências}

ASSUNÇÃO, A. A.; LIMA, F. P. A. Aproximações de Ergonomia ao estudo das exigências afetivas das tarefas. In: GLINA, D. M. R.; ROCHA, L. E. (Orgs.). Saúde Mental no Trabalho da teoria à prática. São Paulo: Ed. Roca, 2010. p. 210-228.

ABRAHĀO, J. I.; PINHO, D. L. M. Teoria e prática ergonômica: seus limites e possibilidades. In: PAZ, M. G. T.; TAMAYO, A. (Orgs.). Escola, Saúde e Trabalho: estudos psicológicos. Brasília: Ed. Universidade de Brasília, 1999. p. 229-240.

BRASIL. Minstério da Saúde. Secretaria de Políticas Públicas de Saúde. Departamento de Atenção Básica. Área Técnica de Saúde do Trabalhador. Brasília: Ministério da Saúde, 2001.

BRASIL. Minstério da Saúde. LER/DORT: protocolos de atenção integrada à saúde do trabalhador de complexidade diferenciada. Brasília: Ministério da Saúde, 2006.

CASAROTTO, R. A.; MENDES, L. F. Queixas, doenças ocupacionais e acidentes de trabalho em trabalhadores de cozinhas industriais. Revista Brasileira de Saude Ocupacional, São Paulo, v. 28, n. 107-108, p. 119-126, nov./dez. 2000.

CHIAVEGATO FILHO, L. G.; PEREIRA JUNIOR, A. LER/DORT: multifatorialidade etiológica e modelos explicativos. Interface: Comunicação, Saúde, Educação, Botucatu, v. 18, n. 14, p. 149-162, set./fev. 2004. http:// dx.doi.org/10.1590/S1414-32832004000100009

COLARES, L. G. T.; FREITAS, C. M. Processo de trabalho e saúde de trabalhadores de uma unidade de alimentação e nutrição: entre a prescrição e o real do trabalho. Cadernos de Saúde Pública, Rio de Janeiro, v. 23, n. 12, p. 3011-3020, 2007. http://dx.doi.org/10.1590/ S0102-311X2007001200022

DUL, J.; WEERDMEESTER, B. Ergonomia Prática. São Paulo: Edgard Blucher, 2004.

FALZON, P. Natureza, objetivos e conhecimentos da ergonomia. In: FALZON, P. Ergonomia. São Paulo: Blucher, 2007. p. 3-19.

FALZON, P.; SAUVAGNAC, C. Carga de trabalho e estresse. In: FALZON, P. Ergonomia. São Paulo: Blucher, 2007. p. 141-154.

GHISLENI, A. P.; MERLO, A. R. C. Trabalhador contemporâneo e patologias por hipersolicitação. Psicologia: Reflexão e Crítica, Porto Alegre, v. 18, n. 2, p. 171-176, maio/ago. 2005. http://dx.doi.org/10.1590/ S0102-79722005000200004

GUÉRIN, F. et al. Compreender o trabalho para transformá-lo: a prática da Ergonomia. São Paulo: Ed. Blucher, 1997.

HAUKKA, E. et al. Co-occurance of musculoskeletal pain among female kitchen workers. International Archives of Occupational and Environmental Health, Berlin, v. 80, n. 2, p. 141-148, Nov 2006. PMid:16688464. http:// dx.doi.org/10.1007/s00420-006-0113-8

LANCMAN, S. Construção de novas teorias e práticas em Terapia Ocupacional, saúde e trabalho. In: LANCMAN, S. (Org.). Saúde, Trabalho e Terapia Ocupacional. São Paulo: Ed. Roca, 2004. cap. 3, p. 71-83.

MENDONÇA JUNIOR, H. P.; ASSUNÇÃO, A. A. Associação entre distúrbios do ombro e trabalho: breve revisão da literatura. Revista Brasileira de Epidemiologia, São Paulo, v. 8, n. 2, p. 167-176, 2005. http://dx.doi. org/10.1590/S1415-790X2005000200009

MERLO, A. R. C. et al. O trabalho entre prazer, sofrimento e adoecimento: a realidade dos portadores de lesões por esforços repetitivos. Psicologia \& Sociedade, Porto Alegre, v. 15, n. 1, p. 117-136, jan./jun. 2003. http://dx.doi.org/10.1590/S0102-71822003000100007

OLIVEIRA, P. A. B. Ergonomia e a organização do trabalho: o papel dos espaços de regulaçáo individual e social na gênese das LER/DORT. Boletim da Saúde, Porto Alegre, v. 19, n. 1, p. 31-38, 2005.

PAIVA, A. C.; CRUZ, A. A. F. Estado nutricional e aspectos ergonômicos de trabalhadores de Unidade de Alimentação e Nutrição. Revista Mineira de Ciências da Saúde, Patos de Minas, v. 1, n. 1, p. 1-11, 2009.

PINHEIRO, F. A.; TRÓCCOLI, B. T.; CARVALHO, C. V. Validação do questionário nórdico de sintomas osteomusculares como medida de morbidade. Revista de Saúde Pública, São Paulo, v. 36, n. 3, p. 307-312, jun. 2002. http://dx.doi.org/10.1590/S0034-89102002000300008 PUNNETT, L.; WEGMAN, D. H. Work-related musculoskeletal disorders: the epidemiologic evidence and the debate. Journal of Electromyography and Kinesiology, New York, v. 14, n. 1, p. 13-23, Feb 2004. PMid:14759746. http://dx.doi.org/10.1016/j.jelekin.2003.09.015

SILVA, E. F.; BRITO, J.; ATHAYDE, M. Trabalho com merendeiras: relaçóes entre atividades de trabalho nas escolas e produção saúde/doença. In: ARAUJO, A. et al. Cenários do trabalho: subjetividade, movimento e enigma. Rio de Janeiro: DP\&A, 2004. cap. 4, p. 89-110. SIQUEIRA, A. R. et al. Estudo e Intervenção, processo de trabalho em um restaurante universitário - em busca de novas metodologias. Revista de Terapia Ocupacional da USP, São Paulo, v. 11, n. 2-3, p. 79-89, maio/dez. 2000.

SMITH, M. J.; CARAYON, P. Work organization, stress, and cumulative trauma disorders. In: MOON, S. D.; SAUTER, S. L. (Eds.). Beyond Biomechanics: Psychosocial aspects of musculoskeletal disorders in office work. London: Taylor \& Francis, 1996. p. 23-42. WISNER, A. A inteligência do trabalho: Textos selecionados em Ergonomia. Sáo Paulo: Ed. Fundacentro, 1994.

\section{Contribuições dos Autores}

Thayná, Janaína e Maria do Carmo trabalharam na concepção. Thayná e Janaína participaram no trabalho de campo, e redação do artigo. Maria do Carmo realizou o trabalho de orientação e supervisão do campo e estudo, revisão e redação do texto final. 